\title{
Separation of Gas Acids by Layered Double Hydroxides
}

\author{
E Butenko* \\ Azov Sea State Technical University, Ukraine \\ *Corresponding author: E Butenko, Azov Sea State Technical University, Ukraine
}

\begin{tabular}{|c|c|}
\hline ARTICLE INFO & ABSTRACT \\
\hline Received: 㸷 April 30, 2019 & Citation: E Butenko. Biomed J Sci \& Tech Res 17(4)-2019. BJSTR. MS.ID.003044. \\
\hline
\end{tabular}

Published: 幽 May 03, 2019

\section{Opinion}

Hydrocarbon synthesis processes are well known and include fixed bed, fluid bed and slurry type processes in which a synthesis gas (syngas) comprising a mixture of $\mathrm{H}_{2}$ and $\mathrm{CO}$ is reacted in the presence of a suitable Fischer-Tropsch type of hydrocarbon synthesis catalyst at conditions effective to form hydrocarbons, and preferably paraffinic hydrocarbons which are solid at standard room temperature conditions of temperature and pressure. The syngas is produced by reacting a low molecular weight hydrocarbon gas with oxygen and steam via well-known processes which include partial oxidation, catalytic steam reforming and combination thereof, using a fixed or fluid catalyst bed. A preferred source of the low molecular weight hydrocarbon is natural gas in which the hydrocarbon comprises primarily methane with minor amounts of $\mathrm{C}_{2}$ hydrocarbons, including $\mathrm{C}^{4+}$ hydrocarbons. Other natural gas components include nitrogen, carbon dioxide, water vapor and sulfur in the form of sulfur bearing compounds including $\mathrm{H}_{2} \mathrm{~S}$, mercaptans, other organic sulfides generally, carbonyl sulfide and sometimes minor amounts of carbon disulfide. Sulfur and other acid substances in the feed to a syngas generator will poison the steam reforming catalyst and result in a loss of syngas productivity.

There are several existing options available for acid substance capture however, each of these systems has its own limitations that impede the technical or economical. Selective adsorption mechanism is a promising technique considered for acid separation. A few inorganic materials such as zeolites, activated carbons, clays were found to have good adsorption capacities of gas acids. However, they are not attractive for separation from wet feeds at high temperatures due to poor hydrothermal stability. Layered double hydroxides are inorganic compounds, and in particular their layered double oxide derivatives produced on calcination have desired properties as acid adsorbents. LDHs were prepared by the co-precipitation of divalent $\mathrm{Mg}$ and trivalent $\mathrm{Al}$ ions in an alkaline solution containing $\mathrm{NaOH}$ and $\mathrm{Na}_{2} \mathrm{CO}_{3}$. Samples were characterized before and after calcination using various techniques such as FTIR, XRD, TGA and XPS. Different LDH samples prepared were screened to identify the samples with optimum sorption properties. Sorption was measured both volumetrically and thermogravimetrically as a function of calcination and sorption temperatures. Reversible desorption capacities were determined using vacuum and temperature cycling methods.

A thorough investigation of aspects pertaining to aging, regeneration, impact of water and sorption potentials of the remaining flue gas components including $\mathrm{CO}_{2}, \mathrm{SO}_{2}$ and $\mathrm{H}_{2} \mathrm{~S}$ was conducted during this research. The findings and discussions from this work provide following major contributions to the gas acids capture research. Significant increase in the sorption capacity of LDHs; recyclability with good sorption and desorption potential and more than $90 \%$ regenerabilty of LDHs; mechanistic aspects of gas acid sorption identified based on heats of adsorption and temperature programmed desorption data; good hydrothermal stability and $\mathrm{SO}_{2}$ sorption; high sorption values and consistent performance even at low partial pressures of gas. The first contribution of this work is related to the synthesis of LDHs leading to best acid sorption capacity. Using novel synthesis procedure an increase of sorption capacity was achieved. This was possible by choosing optimum reactant concentrations and conditions from the large number of LDH samples prepared and tested. In this study different $\mathrm{Mg} / \mathrm{Al}$ ratios were studied and the ration $0,72 \mathrm{~mol} /$ mol were found to be the optimum values leading to high sorption capacity. Further, rate of addition of metal ions and aging of the reaction mixture were also found to produce LDHs with better surface properties including higher surface area. 
Calcination of $\mathrm{LDH}$ at appropriate temperature leading to layered double oxide formation was another important aspect that influenced sorption capacity. We have studied processes of spinel obtaining at different calcing temperature. Calcination temperature of $800^{\circ} \mathrm{C}$ was found ideal for the LDHs prepared with above concentrations. Excellent regenerabilty and stability of the material after repeated vacuum and temperature cycles with good sorption and desorption potential refers to the second contribution of this work. High consistency observed in the sorption and desorption patterns after six cycles demonstrated the stability and recyclability of our material. In all the cases more than $99 \%$ of the original sorption capacity was recovered after regeneration. Aging or storage of LDOs in the atmosphere found to produce significant structural changes leading to the reduction in the sorption capacities. An in-situ calcination method was found to be highly productive and suggested for all sorption measurements of layered double oxide to overcome these losses. High isosteric heat of sorption calculated from the sorption isotherms suggests that it is mostly a chemisorption process. Increase of sorption values with temperature up to $200{ }^{\circ} \mathrm{C}$ also proves that the sorption process involves activation energy.

\section{ISSN: 2574-1241}

DOI: 10.26717/BJSTR.2019.17.003044

E Butenko. Biomed J Sci \& Tech Res

cC $(7)$ This work is licensed under Creative

Submission Link: https://biomedres.us/submit-manuscript.php
TPD results also revealed that only a small amount of total sorption is a weak adsorption. Hence, it is concluded that $\mathrm{CO}_{2}$ sorption on layered double oxides is mostly a chemisorption process rather than physisorption. Finally, $\mathrm{CO}_{2}$ sorption on layered double oxides is explained with a suitable mechanism in correlation with TPD results. Unlike with other solid sorbents such as zeolites, presence of water in the feed proved to have no adverse impact on sorption efficiency of layered double oxides. Water was found to adsorb on layered double oxide simultaneously along with $\mathrm{CO}_{2}$ by increasing the sorption value over the maximum dry $\mathrm{CO}_{2}$ sorption value observed at $200{ }^{\circ} \mathrm{C}$. The water uptake of the layered double oxides which was found to be approximately equal to the difference of wet and dry $\mathrm{CO}_{2}$ sorptions proved that water did not restrict $\mathrm{CO}_{2}$ sorption. Consistent sorption and desorption behavior observed after six temperature cycles also revealed the hydrothermal stability of the sorbent. LDOs found to have very high sorption potential of $\mathrm{SO}_{2}$. Even at low feed concentrations of $\mathrm{SO}_{2}$ the sorption values were very high indicating strong affinity of $\mathrm{SO}_{2}$ for layered double oxides. $\mathrm{SO}_{2}$ sorption was observed to be much stronger as regeneration levels. All the other constituents of flue gas including $\mathrm{NO}_{2}$ showed no sorption property towards layered double oxide.

$\begin{array}{ll}\text { BIOMEDICAL } & \text { Assets of Publishing with us } \\ \text { RESEARCHES } & \text { - Global archiving of articles } \\ & \text { - Immediate, unrestricted online access } \\ & \text { - Rigorous Peer Review Process } \\ \end{array}$

